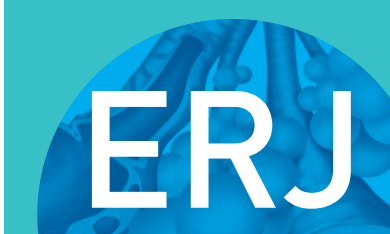

open research
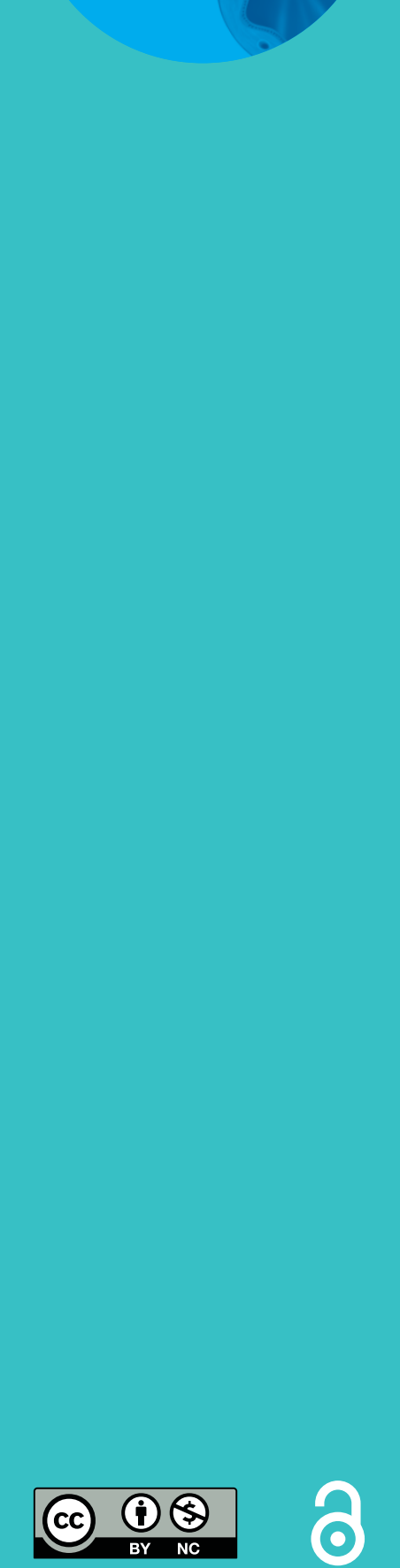

\section{Response to exercise in patients with pulmonary arterial hypertension treated with combination therapy}

\author{
Mari Nishizaki ${ }^{1}$, Aiko Ogawa $\mathbb{( 1}^{2}$ and Hiromi Matsubara $\mathbb{1}^{2,3}$
}

Affiliations: 'Dept of Rehabilitation, National Hospital Organization Okayama Medical Center, Okayama, Japan. ${ }^{2}$ Dept of Clinical Science, National Hospital Organization Okayama Medical Center, Okayama, Japan. ${ }^{3}$ Dept of Cardiology, National Hospital Organization Okayama Medical Center, Okayama, Japan.

Correspondence: Hiromi Matsubara, Depts of Cardiology and Clinical Science, National Hospital Organization Okayama Medical Center, 1711-1 Tamasu, Kita-ku, Okayama 701-1192, Japan. E-mail: matsubara.hiromia gmail.com

ABSTRACT Pulmonary arterial hypertension (PAH)-specific combination therapy improves pulmonary haemodynamics at rest in patients with $\mathrm{PAH}$; nevertheless, exertional dyspnoea remains. We investigated pulmonary haemodynamic response to exercise, and the relationship to ventilatory efficiency and hypoxaemia in patients with $\mathrm{PAH}$ treated with combination therapy. 32 clinically stable patients with $\mathrm{PAH}$ undergoing combination therapy underwent cardiopulmonary exercise testing with right heart catheterisation. Haemodynamic impairment was moderate to severe before treatment. However, after treatment it was significantly improved, and the mean pulmonary arterial pressure (mPAP) at rest was $<25 \mathrm{mmHg}$ in 13 patients. The mPAP increased significantly from $27.9 \pm 10.7$ to $45.9 \pm 16.7 \mathrm{mmHg}(\mathrm{p}<0.01)$ during exercise. The cardiac index increased inadequately, and the total pulmonary resistance (TPR) increased significantly from $5.74 \pm 3.42$ to $6.58 \pm 3.82$ Wood units $(\mathrm{p}<0.01)$. The $\mathrm{mPAP} /$ cardiac output $(\mathrm{CO})$ slope was steep $\left(10.0 \pm 6.7 \mathrm{mmHg} \cdot \mathrm{min} \cdot \mathrm{L}^{-1}\right)$. It significantly correlated with both the minute ventilation/ carbon dioxide output slope $(\mathrm{r}=0.51, \mathrm{p}<0.01)$ and peripheral arterial oxygen saturation/workload slope $(\mathrm{r}=-0.41, \mathrm{p}=0.02)$. In addition, the $\mathrm{mPAP} / \mathrm{CO}$ slope correlated significantly with $\mathrm{mPAP}$ at rest $(\mathrm{r}=0.73$, $\mathrm{p}<0.01)$ and TPR at rest $(\mathrm{r}=0.64, \mathrm{p}<0.01)$. Even after pulmonary haemodynamics at rest was significantly improved in PAH patients with PAH-specific combination therapy, the mPAP/CO slope was steep and the steep $\mathrm{mPAP} / \mathrm{CO}$ slope related to decreased ventilatory efficiency and the severity of hypoxaemia. The $\mathrm{mPAP} / \mathrm{CO}$ slope was steeper in patients with higher MPAP and TPR at rest.

$@$ ERSpublications

Even after pulmonary haemodynamics at rest are improved in $\mathrm{PAH}$ patients with combination therapy, pulmonary haemodynamic response to exercise is abnormal, and related to abnormal respiratory response and the severity of hypoxaemia https://bit.ly/2HGSOTX

Cite this article as: Nishizaki M, Ogawa A, Matsubara H. Response to exercise in patients with pulmonary arterial hypertension treated with combination therapy. ERJ Open Res 2021; 7: 007252020 [https://doi.org/10.1183/23120541.00725-2020].

This article has supplementary material available from openres.ersjournals.com.

Received: 5 Oct 2020 | Accepted: 20 Oct 2020

Copyright $\odot$ ERS 2021. This article is open access and distributed under the terms of the Creative Commons Attribution Non-Commercial Licence 4.0. 


\section{Introduction}

Pulmonary arterial hypertension (PAH) is characterised by pulmonary haemodynamic dysfunction, leading to elevation of pulmonary arterial pressure and progressive right heart failure [1]. However, PAH-specific therapy, which includes selective pulmonary vasodilators, improves pulmonary haemodynamics at rest, exercise capacity, quality of life and prognosis [2-4]. Currently, combination therapy is the most widely utilised strategy, and randomised controlled trials have shown its efficacy on the improvement of exercise capacity and the reduction of time to clinical worsening [5]. We demonstrated that pulmonary haemodynamics at rest were remarkably improved and survival was good in Japanese patients with idiopathic/heritable $\mathrm{PAH}$, most of whom were receiving combination therapy [6]; however, exertional dyspnoea remained in some patients. McLAUGHLin et al. [7] reported that there was no improvement in Borg dyspnoea score even after combination therapy. Exertional dyspnoea in patients with PAH can be related to ventilation/perfusion mismatching due to hypoperfusion of ventilated alveoli during exercise [8]. We hypothesised that pulmonary haemodynamic response to exercise was impaired in patients with PAH even after pulmonary haemodynamics at rest were improved with combination therapy, and that it related to ventilatory efficiency and hypoxaemia during exercise. In addition, we hypothesised that the impairment of pulmonary haemodynamic response would depend on pulmonary haemodynamics at rest.

\section{Material and methods \\ Study participants}

From June 2009 to April 2018, 141 patients with PAH consecutively underwent haemodynamic studies with right heart catheterisation during follow-up at the National Hospital Organization Okayama Medical Center (Okayama, Japan). The diagnosis of PAH was established using standard criteria [9]. The exclusion criteria for cardiopulmonary exercise testing (CPET) with right heart catheterisation were as follows: monotherapy; treatment with PAH-specific therapy in other hospitals for $>1$ year; mild PAH (mean pulmonary arterial pressure ( $\mathrm{mPAP})<30 \mathrm{mmHg}$ ) at the initiation of $\mathrm{PAH}$-specific therapy at our hospital; under-optimisation of treatment regimen of $\mathrm{PAH}$-specific therapy; concomitant treatment with surgery (e.g. closure of shunt); World Health Organization (WHO) functional class IV; 6-min walk distance

141 patients with $\mathrm{PAH}$ consecutively underwent right heart catheterisation for clinical follow-up from June 2009 to April 2018

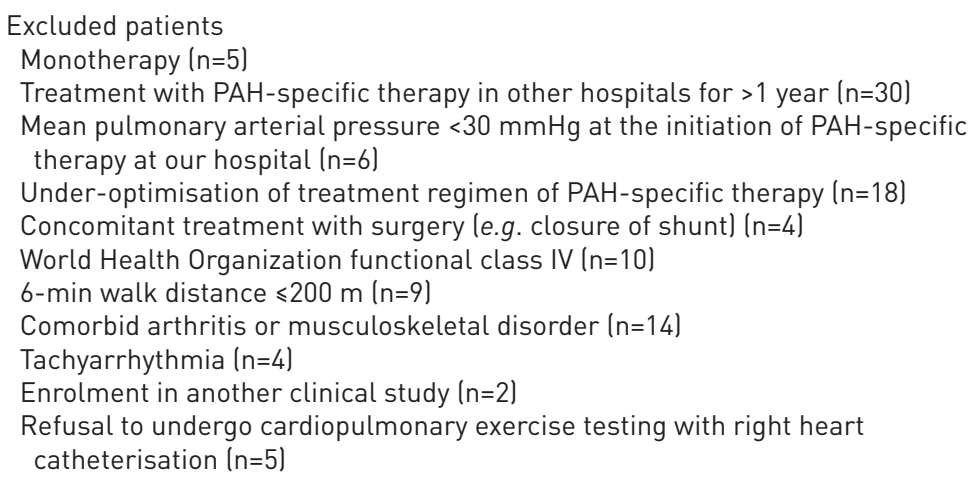

32 patients were enrolled in this study

FIGURE 1 Flow diagram of patient population for study inclusion. PAH: pulmonary arterial hypertension. 
$\leqslant 200 \mathrm{~m}$; comorbid arthritis or musculoskeletal disorder; tachyarrhythmia; and enrolment in another clinical study. After providing informed consent, 34 patients underwent CPET with right heart catheterisation (figure 1). This study was approved by the institutional review board at National Hospital Organization Okayama Medical Center (approval number 2018-028). All patients were referred from other hospitals with or without PAH-specific therapy. Clinical parameters had been evaluated at the initiation of PAH-specific therapy in our hospital, indicated as baseline. The parameters were evaluated when CPET was performed, indicated as study enrolment. Blood samples were drawn from a peripheral vein and brain natriuretic peptide levels were measured. Pulmonary functions were tested using a spirometer (CHESTAC-3000; Chest, Tokyo, Japan, or FUDAC-77; Fukuda Denshi, Tokyo, Japan). Vital capacity, forced expiratory volume in $1 \mathrm{~s}$ and diffusing capacity of the lungs for carbon monoxide $\left(D_{\mathrm{LCO}}\right)$ were evaluated. The 6-min walk test was performed according to the guidelines [10].

\section{CPET with right heart catheterisation}

A Swan-Ganz catheter (AK-09903-J; Arrow Teleflex Medical, Wayne, PA, USA) was inserted via the internal jugular vein into the pulmonary artery, and haemodynamic parameters were assessed at rest in the supine position in the catheterisation laboratory. The mPAP, pulmonary artery wedge pressure and cardiac output $(\mathrm{CO})$ were evaluated using the Fick method during right heart catheterisation. Cardiac index was calculated as CO divided by body surface area. After preparation within $30 \mathrm{~min}$, CPET with right heart catheterisation was performed to evaluate pulmonary haemodynamic and respiratory response to exercise. Patients were carefully assisted onto a semi-supine cycle ergometer (Strength Ergo 240 BK-ERG-003; Mitsubishi Electric Engineering, Tokyo, Japan), which was set at an angle of $40^{\circ}$, with legs comfortably positioned. After resting for $3 \mathrm{~min}$, the patients started warm-up cycling at $0 \mathrm{~W}$ for $2 \mathrm{~min}$. The workload during exercise was increased by $1 \mathrm{~W}$ every $12 \mathrm{~s}$. Patients were instructed to maintain cycling at the speed of 50-55 rotations per minute. Cardiac activity and peripheral arterial oxygen saturation $\left(S_{\mathrm{pO}_{2}}\right)$ were continuously monitored using a standard 12-lead electrocardiogram and pulse oximeter, respectively, and noninvasive systolic blood pressure at the brachial artery with a sphygmomanometer was measured every minute. Because mPAP and mean right atrial pressure are easily influenced by breathing, the values measured during expiration were recorded. Cardiac index and mixed venous oxygen saturation were monitored using continuous CO monitoring (Vigilance Monitor; Edwards Lifesciences, Irvine, CA, USA). Cardiac index was measured using the thermodilution method every minute, and three consecutive values were averaged. All these parameters were recorded per minute. Patients performed submaximal symptom-limited exercise. According to the guidelines, the criteria for the CPET termination were as follows: dizziness, chest pain, ischaemic electrocardiographic changes, significant arrhythmia, fall in systolic blood pressure $(>20 \mathrm{mmHg}$ from the highest value during the test), hypertension (systolic blood pressure $>220 \mathrm{mmHg}$ ), severe elevation in $\mathrm{mPAP}(>70 \mathrm{mmHg})$, desaturation $\left(S_{\mathrm{PO}_{2}}<88 \%\right)$ and reaching targeted heart rate, which was calculated as $(220-$ age $) \times 0.8$ [11]. The CPET was performed by several medical staff trained for emergencies. Total pulmonary resistance (TPR) was calculated as mPAP divided by $\mathrm{CO}$. The $\mathrm{mPAP} /$ workload slope was calculated as the change in $\mathrm{mPAP}$ from rest to peak exercise divided by peak workload, and the $S_{\mathrm{pO}_{2}}$ /workload slope was calculated as the change in $S_{\mathrm{pO}_{2}}$ from rest to peak exercise divided by peak workload. The $\mathrm{mPAP} / \mathrm{CO}$ slope, a parameter of pulmonary haemodynamic response to exercise, was calculated as the change in mPAP from rest to peak exercise divided by the change in $\mathrm{CO}$ from rest to peak exercise.

In addition, the levels of respiratory gases were measured breath-by-breath using an aero monitor (AE-300S; Minato Medical Science, Osaka, Japan, or Cpex-1; Inter Reha, Osaka, Japan) during exercise. Oxygen uptake $\left(V^{\prime} \mathrm{O}_{2}\right)$, carbon dioxide output $\left(V^{\prime} \mathrm{CO}_{2}\right)$ and minute ventilation $\left(V_{\mathrm{E}}^{\prime}\right)$ were monitored continuously. Anaerobic threshold was determined using the V-slope method or the ventilatory equivalents method [12]. As a parameter of ventilatory efficiency, $V^{\prime}{ }_{\mathrm{E}} / V^{\prime} \mathrm{CO}_{2}$ slope was evaluated. It was determined by linear regression of $V^{\prime}$ versus $V_{\mathrm{CO}_{2}}^{\prime}$ from start of exercise to the respiratory compensation point for metabolic acidosis.

\section{Statistical analysis}

All parameters were expressed as mean \pm SD. Because brain natriuretic peptide levels were not normally distributed, median values were exceptionally adopted. The WHO functional class was expressed as the median, and the changes in the number of patients in each class were evaluated using the Wilcoxon signed-rank test. The changes in the number of PAH-specific therapy were evaluated using the McNemar test. The parameters between the two groups were compared using the paired t-test. Linear regression analysis (Pearson's correlation) was used to calculate the correlations among parameters. All analyses were performed using IBM SPSS Statistics 20 (IBM, Armonk, NY, USA). p-values <0.05 were considered statistically significant. 


\section{Results}

\section{Patient characteristics}

We performed CPET with right heart catheterisation for 34 patients with PAH undergoing combination therapy. After two patients with poor recordings during CPET were excluded, 32 patients were enrolled in the study (figure 1). The patient characteristics are shown in table 1. The study population included 29 (91\%) females. 22 patients had idiopathic/heritable PAH. Seven patients had PAH associated with connective tissue disease: three had systemic lupus erythematosus, three had mixed connective tissue disease and one had systemic sclerosis. PAH was associated with congenital heart disease in two patients and portal hypertension in one patient. At baseline, PAH-specific therapy had already been induced in 17 (53\%) patients at their previous hospitals; however, only six (19\%) patients were undergoing combination therapy. After being referred to our hospital, PAH-specific drugs were initiated or added, and all patients were undergoing combination therapy at study enrolment: dual therapy $n=13(41 \%)$, triple therapy $n=19$ (59\%). At study enrolment, 26 (81\%) patients were treated with intravenous epoprostenol $\left(66.4 \pm 32.9 \mathrm{ng} \cdot \mathrm{kg}^{-1} \cdot \mathrm{min}^{-1}\right.$, duration $\left.61.1 \pm 47.3 \mathrm{months}\right)$. Most patients had been classified in WHO functional class III or IV at baseline; however, after $55.2 \pm 45.2$ months of PAH-specific therapy at our hospital, all patients improved to class I or II at study enrolment. Brain natriuretic peptide levels improved significantly. $D_{\text {LCO }}$ levels at baseline were not available for two patients. $D_{\text {LCO }}$ improved significantly at study enrolment; however, the values were not within the normal limits. Haemodynamic impairment of mPAP, cardiac index and pulmonary vascular resistance (PVR) had been moderate to severe at baseline; however, remarkable improvement was seen with the combination therapy at study enrolment. mPAP $<25 \mathrm{mmHg}$ at rest was obtained in 13 patients. In addition, 6-min walk distance significantly improved.

\section{Pulmonary haemodynamic and respiratory response during exercise}

All 32 patients underwent successful CPET, with no adverse events during the test. The end-point was leg fatigue in 11 patients, dyspnoea in eight patients, both leg fatigue and dyspnoea in 10 patients and severe

\begin{tabular}{|c|c|c|c|}
\hline & Baseline & Study enrolment & p-value \\
\hline Male/female & \multicolumn{2}{|c|}{$3 / 29$} & \\
\hline Age years & $28.5 \pm 10.3$ & $33.0 \pm 10.1$ & $<0.01$ \\
\hline Body mass index $\mathrm{kg} \cdot \mathrm{m}^{-2}$ & $20.7 \pm 3.0$ & $19.8 \pm 2.6$ & 0.09 \\
\hline WHO functional class ${ }^{\#}$ (I/II/III/IV) & III (0/6/14/12) & || $(7 / 25 / 0 / 0)$ & $<0.01$ \\
\hline \multicolumn{4}{|l|}{ PAH-specific therapy } \\
\hline Intravenous epoprostenol & $1(3)$ & $26(81)$ & $<0.01$ \\
\hline Beraprost & $11(34)$ & $5(16)$ & 0.18 \\
\hline Endothelin receptor antagonist & $9(28)$ & $30(94)$ & $<0.01$ \\
\hline Phosphodiesterase type 5 inhibitor & 6 (19) & $21(66)$ & $<0.01$ \\
\hline Soluble guanylate cyclase stimulator & $0(0)$ & $1(3)$ & \\
\hline \multicolumn{4}{|l|}{ Combination therapy } \\
\hline Dual therapy & $2(6)$ & $13(41)$ & $<0.01$ \\
\hline Triple therapy & $4(13)$ & 19 (59) & $<0.01$ \\
\hline \multicolumn{4}{|l|}{ Laboratory parameters } \\
\hline $\mathrm{BNP} \mathrm{pg} \cdot \mathrm{mL}^{-1}$ & $334.5[8.7-1687.6]$ & $10.3(5.8-131.7)$ & $<0.01$ \\
\hline \multicolumn{4}{|l|}{ Respiratory parameters } \\
\hline Vital capacity \% predicted & $89.9 \pm 17.2$ & $93.7 \pm 14.4$ & 0.03 \\
\hline $\mathrm{FEV}_{1} / \mathrm{FVC} \%$ & $84.1 \pm 7.3$ & $82.5 \pm 7.2$ & 0.24 \\
\hline$D_{\text {Lco }} \%$ predicted & $58.5 \pm 12.6$ & $66.3 \pm 10.8$ & $<0.01$ \\
\hline \multicolumn{4}{|l|}{ Pulmonary haemodynamic parameters } \\
\hline PAWP $\mathrm{mmHg}$ & $8.3 \pm 3.4$ & $7.9 \pm 3.2$ & 0.57 \\
\hline $\mathrm{mPAP} \mathrm{mmHg}$ & $61.8 \pm 18.3$ & $28.7 \pm 12.2$ & $<0.01$ \\
\hline Cardiac index $\mathrm{L} \cdot \mathrm{min}^{-1} \cdot \mathrm{m}^{-2}$ & $2.17 \pm 0.66$ & $3.59 \pm 0.89$ & $<0.01$ \\
\hline PVR Wood units & $18.3 \pm 8.0$ & $4.3 \pm 2.9$ & $<0.01$ \\
\hline \multicolumn{4}{|l|}{ Exercise capacity } \\
\hline 6MWD m & $287.3 \pm 117.1$ & $449.7 \pm 69.2$ & $<0.01$ \\
\hline
\end{tabular}

Data are presented as $\mathrm{n}$, mean $\pm \mathrm{SD}, \mathrm{n}(\%)$ or median (range), unless otherwise stated. WHO: World Health Organization; PAH: pulmonary arterial hypertension; BNP: brain natriuretic peptide; $\mathrm{FEV}_{1}$ : forced expiratory volume in $1 \mathrm{~s}$; FVC: forced vital capacity; $D_{\text {LCo }}$ : diffusing capacity of the lung for carbon monoxide; PAWP: pulmonary artery wedge pressure; mPAP: mean pulmonary arterial pressure; PVR: pulmonary vascular resistance; 6MWD: 6-min walk distance. ${ }^{\#}$ : median (n). 
elevation of mPAP in three patients. Workload at peak exercise was $37.7 \pm 11.3 \mathrm{~W}$. Haemodynamic and oxygen parameters during CPET are shown in table 2 and figure 2. The mPAP significantly increased from $27.9 \pm 10.7$ to $45.9 \pm 16.7 \mathrm{mmHg}$ (figure $2 \mathrm{a}$ ). Cardiac index increased inadequately from $3.72 \pm 0.85$ to $5.35 \pm 1.20 \mathrm{~L} \cdot \mathrm{min}^{-1} \cdot \mathrm{m}^{-2}$ (figure $2 \mathrm{~b}$ ). As a result, TPR increased from $5.74 \pm 3.42$ to $6.58 \pm 3.82$ Wood units (figure 2c). $S_{\mathrm{pO}_{2}}$ decreased from $97.0 \pm 1.2 \%$ to $94.0 \pm 2.7 \%$ (figure $2 \mathrm{~d}$ ). $S_{\mathrm{pO}_{2}}$ at rest was $\geqslant 95 \%$ in all 32 patients; however, $S_{\mathrm{pO}_{2}}$ at peak exercise was $<90 \%$ in four patients. The $\mathrm{mPAP} /$ workload slope significantly correlated with $\mathrm{mPAP}$ at rest $(\mathrm{r}=0.78, \mathrm{p}<0.01)$ (supplementary figure $\mathrm{S} 1$ ). The $\mathrm{mPAP} / \mathrm{CO}$ slope was $10.0 \pm 6.7 \mathrm{mmHg} \cdot \mathrm{min} \cdot \mathrm{L}^{-1}$, and it was $>3 \mathrm{mmHg} \cdot \mathrm{min} \cdot \mathrm{L}^{-1}$ in 28 patients (figure 3 ). This result indicated that the pulmonary haemodynamic response to exercise was impaired in most of the patients, despite remarkable improvement in pulmonary haemodynamics at rest with combination therapy. Conversely, 10 out of 13 patients whose mPAP at rest was $<25 \mathrm{mmHg}$ met the criterion of mPAP at peak exercise $\leqslant 30 \mathrm{mmHg}$ or TPR at peak exercise $\leqslant 3$ Wood units (normalised resting pulmonary hypertension without exercise-induced pulmonary hypertension), although their pulmonary haemodynamic impairment at baseline was severe (mPAP $52.2 \pm 9.5 \mathrm{mmHg}$, PVR 17.8 \pm 4.9 Wood units).

Respiratory parameters during CPET are indicated in table 3. Peak $V_{\mathrm{O}_{2}}^{\prime}$ /weight and $V^{\prime} \mathrm{O}_{2}$ at anaerobic threshold/weight decreased moderately compared with predicted values. Peak $V_{\mathrm{O}_{2}}^{\prime} /$ weight did not significantly correlate with the mPAP/CO slope $(\mathrm{r}=-0.09, \mathrm{p}=0.62)$; however, it correlated with cardiac index at peak exercise $(\mathrm{r}=0.39, \mathrm{p}=0.03)$. The $V_{\mathrm{E}}^{\prime} / V^{\prime} \mathrm{CO}_{2}$ slope increased, as compared with that of normal subjects [13].

\section{Correlation between pulmonary haemodynamic response and parameters at rest and during exercise}

The mPAP/CO slope significantly correlated with the $V^{\prime}{ }_{\mathrm{E}} / V^{\prime} \mathrm{CO}_{2}$ slope $(\mathrm{r}=0.51, \mathrm{p}<0.01)$ (figure $\left.4 \mathrm{a}\right)$, and it correlated negatively with the $S_{\mathrm{pO}_{2}} /$ workload slope $(\mathrm{r}=-0.41, \mathrm{p}=0.02)$ (figure $\left.4 \mathrm{~b}\right)$. The $\mathrm{mPAP} / \mathrm{CO}$ slope tended to shift upward and become steeper as the level of mPAP at rest increased (figure 3). We investigated the correlation between the mPAP/CO slope and parameters at rest and during exercise (table 4). The mPAP/CO slope significantly correlated with mPAP at rest $(r=0.73, p<0.01)$ and TPR at rest $(\mathrm{r}=0.64, \mathrm{p}<0.01)$; however, it did not correlate with other haemodynamic, oxygen and respiratory parameters at rest.

\section{Discussion}

Pulmonary haemodynamic and respiratory response during exercise

Pulmonary circulation is a lower pressure and lower vascular resistance system compared with systemic circulation, due to the high compliance of the right ventricular-pulmonary vascular bed unit under normal conditions. In addition, pulmonary circulation has a large reserve capacity; that is, pulmonary vessels can be distended and recruited when blood flow increases [14]. For these reasons, PVR decreases during exercise and it leads to a slight increase in pulmonary arterial pressure, even with increased CO. This physiology was confirmed in the systematic review based on right heart catheterisation in 1187 healthy participants from 47 studies in 13 countries, and mPAP during exercise was dependent on exercise level and age [15]. Tolle et al. [16] demonstrated that mPAP increased from 13.9 to only $27.4 \mathrm{mmHg}$, and PVR decreased from 154 to $62 \mathrm{dyn} \cdot \mathrm{s} \cdot \mathrm{cm}^{-5}$ (from 1.9 to 0.8 Wood units) at the maximal workload under the stress of incremental cycling exercise in 16 normal participants. According to the review by LEWIs et al. [17], invasive or noninvasive studies in healthy participants showed that the $\mathrm{mPAP} / \mathrm{CO}$ slope ranged from

TABLE 2 Haemodynamic and oxygen parameters during cardiopulmonary exercise testing

\begin{tabular}{|c|c|c|c|c|}
\hline & Rest & Peak exercise & Change & p-value \\
\hline sBP mmHg & $104.0 \pm 10.4$ & $127.8 \pm 19.4$ & +23 & $<0.01$ \\
\hline Heart rate bpm & $82.4 \pm 12.0$ & $121.9 \pm 14.7$ & +50 & $<0.01$ \\
\hline mRAP $\mathrm{mmHg}$ & $3.6 \pm 2.0$ & $6.4 \pm 2.2$ & +121 & $<0.01$ \\
\hline mPAP mmHg & $27.9 \pm 10.7$ & $45.9 \pm 16.7$ & +67 & $<0.01$ \\
\hline Cardiac index L. $\min ^{-1} \cdot \mathrm{m}^{-2}$ & $3.72 \pm 0.85$ & $5.35 \pm 1.20$ & +46 & $<0.01$ \\
\hline TPR Wood units & $5.74 \pm 3.42$ & $6.58 \pm 3.82$ & +17 & $<0.01$ \\
\hline $\mathrm{S}_{\mathrm{pO}_{2}} \%$ & $97.0 \pm 1.2$ & $94.0 \pm 2.7$ & -3.1 & $<0.01$ \\
\hline $\mathrm{S}_{\mathrm{vO}_{2}} \%$ & $76.8 \pm 4.2$ & $53.5 \pm 7.6$ & -30 & $<0.01$ \\
\hline
\end{tabular}

Data are presented as mean \pm SD or \%. sBP: systolic blood pressure; mRAP: mean right atrial pressure; mPAP: mean pulmonary arterial pressure; TPR: total pulmonary resistance; $S_{\mathrm{pO}_{2}}$ : peripheral arterial oxygen saturation; $\mathrm{S}_{\mathrm{vO}_{2}}$ : mixed venous oxygen saturation. 

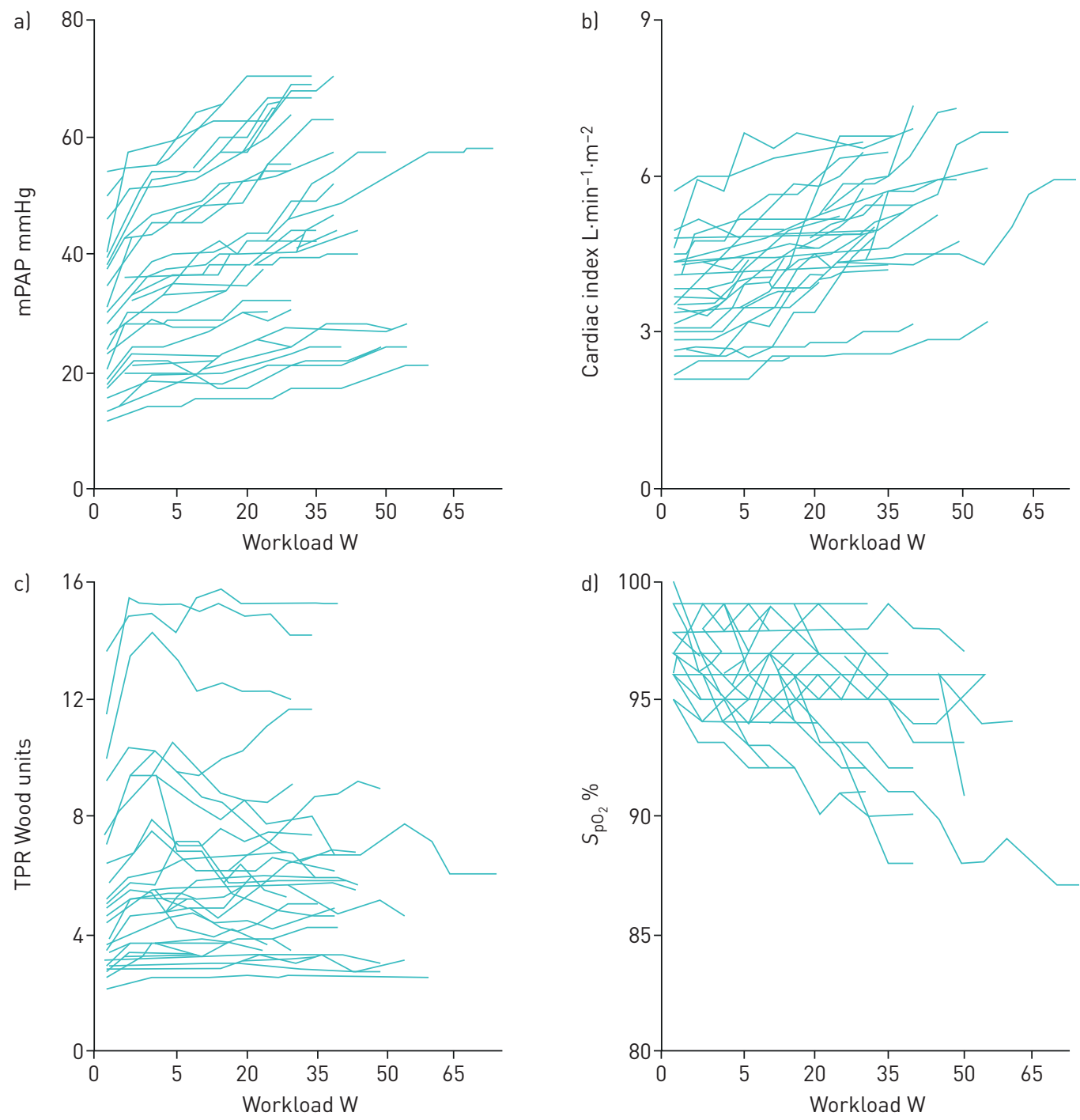

FIGURE 2 Haemodynamic and oxygen parameters during cardiopulmonary exercise testing in patients with pulmonary arterial hypertension. a) mean pulmonary arterial pressure (mPAP); b) cardiac index; c) total pulmonary resistance (TPR); d) peripheral arterial oxygen saturation $\left(\mathrm{S}_{\mathrm{pO}_{2}}\right)$.

0.9 to $2.5 \mathrm{mmHg} \cdot \mathrm{min} \cdot \mathrm{L}^{-1}$. However, this response could be impaired in patients with $\mathrm{PAH}$ due to pulmonary vascular remodelling. Decreased reserve capacity in the pulmonary vascular bed would bring a remarkable increase in $\mathrm{mPAP}$ and PVR, resulting in the steeper mPAP/CO slope. Although the data on $\mathrm{PAH}$ patients are limited, Blumberg et al. [18] indicated that constant exercise on a $45^{\circ}$-upright cycle ergometer increased mPAP from 45 to $70 \mathrm{mmHg}$ and PVR from 904 to $1013 \mathrm{dyn} \cdot \mathrm{s} \cdot \mathrm{cm}^{-5}$ (from 11.3 to 12.7 Wood units) in 16 patients with pulmonary hypertension including PAH. In the review by LEWIS et al. [17], the mPAP/CO slope in patients with $\mathrm{PAH}$, whose $\mathrm{mPAP}$ at rest was $>40 \mathrm{mmHg}$, ranged from 6.1 to $11.9 \mathrm{mmHg} \cdot \mathrm{min} \cdot \mathrm{L}^{-1}$. Another study reported that the steep $\mathrm{mPAP} / \mathrm{cardiac}$ index slope existed in $\mathrm{PAH}$ patients whose mPAP at rest was still high despite $\mathrm{PAH}$-specific therapy $[19,20]$. In the present study, even though mPAP at rest was much lower, the mPAP/CO slopes in most patients remained steep. This result suggests that reserve capacity in the pulmonary vascular bed did not recover sufficiently. Recently, combining mPAP $>30 \mathrm{mmHg}$ and TPR $>3$ Wood units during exercise has been proposed as the criterion for diagnosis of exercise pulmonary hypertension [21]. 10 patients in the present study met the criteria of $\mathrm{mPAP}$ at rest $<25 \mathrm{mmHg}$ and $\mathrm{mPAP}$ at peak exercise $\leqslant 30 \mathrm{mmHg}$ or $\mathrm{TPR}$ at peak exercise $\leqslant 3$ Wood units (normalised resting pulmonary hypertension without exercise-induced pulmonary hypertension), although their pulmonary haemodynamic impairment before treatment was severe. Exercise capacity was moderately reduced. The subjective exercise limitation in most patients was leg fatigue and/or dyspnoea. The objective exercise limitation was not mPAP/CO slope, but cardiac output. 
FIGURE 3 The mean pulmonary arterial pressure (mPAP)/cardiac output slope during cardiopulmonary exercise testing in patients with pulmonary arterial hypertension. The broken line represents mPAP at rest of $30 \mathrm{mmHg}$ and the dotted line represents the $\mathrm{mPAP} / \mathrm{cardiac}$ output slope of $3 \mathrm{mmHg} \cdot \mathrm{min} \cdot \mathrm{L}^{-1}$.

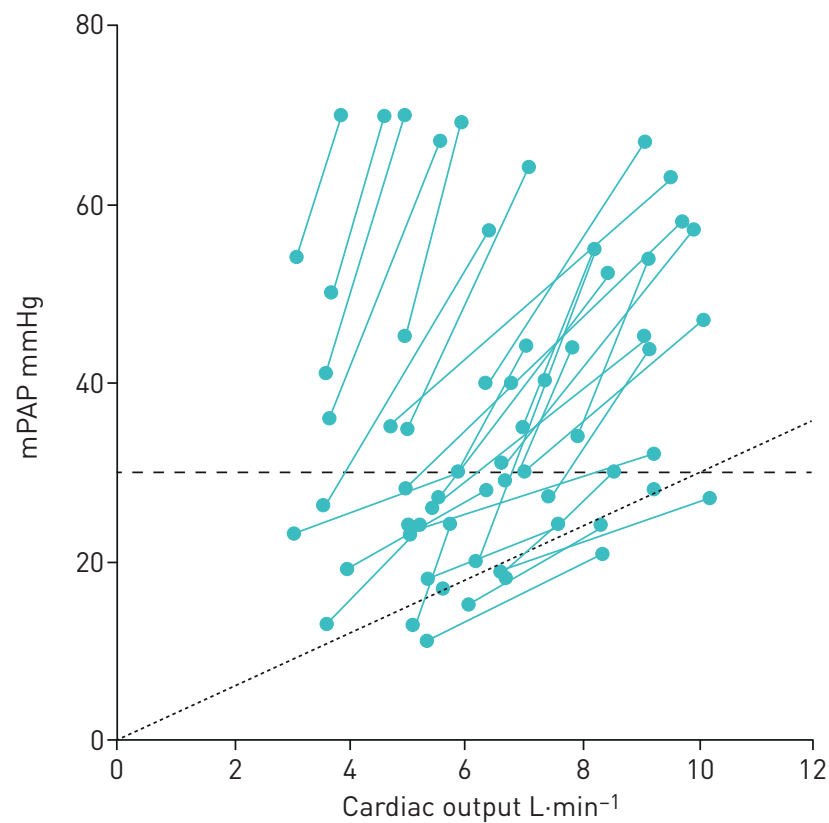

\section{Correlation between pulmonary haemodynamic response and parameters at rest and during} exercise

It has been shown that the steep $V_{\mathrm{E}}^{\prime} / V^{\prime} \mathrm{CO}_{2}$ slope was related to both resting and exercise PVR in patients with group II pulmonary hypertension [22]. $V^{\prime}{ }_{\mathrm{E}} / V^{\prime} \mathrm{CO}_{2}$ is determined by two factors: ratio of dead space to tidal volume and arterial carbon dioxide tension [23]. In patients with idiopathic $\mathrm{PAH}$, the ventilation of underperfused alveoli causes an increase in dead space ventilation, manifested by a hyperbolic increase in $V_{\mathrm{E}}^{\prime}$ relative to the $V^{\prime} \mathrm{CO}_{2}$ increase during exercise [8]. In the present study, we demonstrated that the mPAP/CO slope significantly correlated with the $V^{\prime}{ }_{E} / V^{\prime} \mathrm{CO}_{2}$ slope. This suggests the possibility that hypoperfusion of ventilated alveoli due to impaired pulmonary haemodynamic response to exercise increased dead space, resulting in a steep $V^{\prime}{ }_{\mathrm{E}} / V^{\prime} \mathrm{CO}_{2}$ slope. Furthermore, we found that the mPAP/CO slope significantly correlated with the $\mathrm{S}_{\mathrm{pO}_{2}}$ /workload slope. This result suggests that reduced pulmonary capillary bed due to impaired pulmonary haemodynamic response would also influence hypoxaemia during exercise. Exertional dyspnoea in patients with PAH can be attributed to at least three mechanisms that increase ventilatory drive: the first is ventilation/perfusion mismatching, resulting in an increased ratio of dead space to tidal volume due to hypoperfusion of ventilated alveoli; the second is the increased hydrogen ion stimulus to ventilation resulting from a low-workload lactic acidosis; and the third is arterial hypoxaemia due to reduced pulmonary capillary bed or right-to-left shunt through a patent foramen ovale [8]. We demonstrated the possibility of hypoperfusion of ventilated alveoli and hypoxaemia in the present study. These factors might cause residual exertional dyspnoea.

In a prior study, it was shown that the mPAP/CO slope significantly correlated with mPAP at rest in several patients with $\mathrm{PAH}$ [24]. We investigated the correlation between the $\mathrm{mPAP} / \mathrm{CO}$ slope and parameters at rest and during exercise in more patients with $\mathrm{PAH}$. The $\mathrm{mPAP} / \mathrm{CO}$ slope significantly

\section{TABLE 3 Respiratory parameters during cardiopulmonary exercise testing}

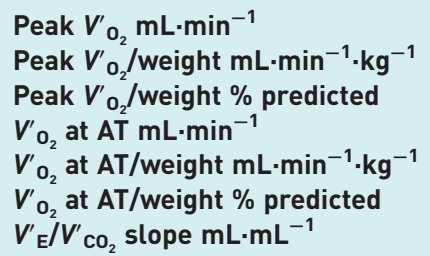



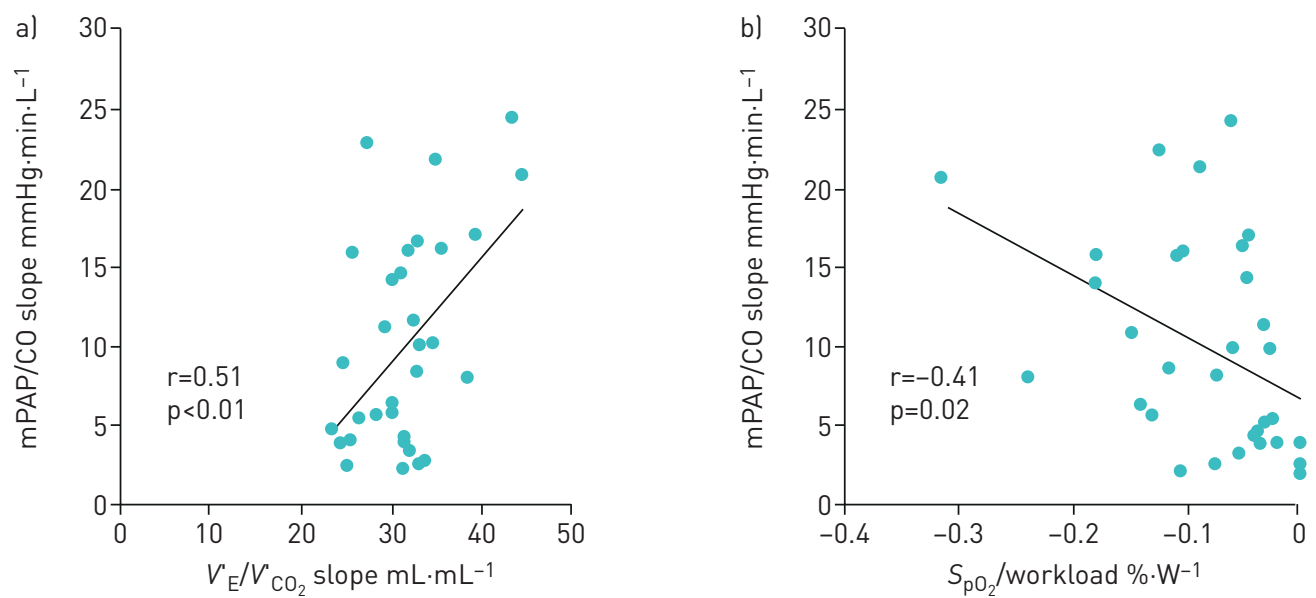

FIGURE 4 Correlation between the mean pulmonary arterial pressure (mPAP)/cardiac output (CO) slope and parameters during cardiopulmonary exercise testing in patients with pulmonary arterial hypertension. a) Minute ventilation $\left(V^{\prime}{ }^{\prime}\right) /$ carbon dioxide output $\left(V^{\prime} \mathrm{CO}_{2}\right)$ slope; b) peripheral arterial oxygen saturation $\left(S_{\mathrm{pO}_{2}}\right) /$ workload slope. The continuous lines indicate the regression lines.

correlated with mPAP and TPR at rest. This result suggests that the impairment of pulmonary haemodynamic response could be predicted by the severity of pulmonary haemodynamics at rest.

We recommend investigation of the pulmonary and respiratory response by CPET with right heart catheterisation before a rehabilitation programme is started for all PAH patients; however, it is difficult when haemodynamic impairment is severe. Based on the findings of a steeper mPAP/CO slope in patients with higher mPAP and TPR at rest, patients with severe PAH should avoid excessive exercise training, because the right ventricular overload during exercise would be much higher in these patients, even if the exercise load is the same.

\section{Study limitations}

This study has some limitations. First, the size of the patient population was small. Second, patients with $\mathrm{mPAP}<30 \mathrm{mmHg}$ at the initiation of PAH-specific therapy at our hospital were not included and it is not known if our results apply to patients with mild PAH. Third, we evaluated vascular resistance using TPR and not PVR, because pulmonary artery wedge pressure as an estimate of left atrial pressure was

TABLE 4 Correlation between the mean pulmonary arterial pressure (mPAP)/cardiac output

slope and parameters at rest and during the exercise

p-value

At rest
mPAP
Cardiac index
$\mathrm{TPR}$
$\mathrm{S}_{\mathrm{pO}_{2}}$
$\mathrm{~S}_{\mathrm{vO}_{2}}$
Vital capacity
$\mathrm{FEV} / \mathrm{FVC}$
$D_{\mathrm{LCO}}$
At peak exercise
mPAP
Cardiac index
$\mathrm{TPR}$
$\mathrm{S}_{\mathrm{pO}_{2}}$
$\mathrm{~S}_{\mathrm{VO}_{2}}$

0.73

$<0.01$

$-0.15$

0.64

$-0.03$

$-0.15$

0.33

$-0.15$

0.05

0.70

$-0.60$

0.80

$-0.19$

$-0.15$

TPR: total pulmonary resistance; $S_{\mathrm{pO}_{2}}$ : peripheral arterial oxygen saturation; $S_{\mathrm{vO}_{2}}$ : mixed venous oxygen saturation; $\mathrm{FEV}_{1}$ : forced expiratory volume in $1 \mathrm{~s}$; FVC: forced vital capacity; $D_{\mathrm{Lco}}$ : diffusing capacity of the lung for carbon monoxide. 
technically difficult to evaluate at peak exercise. The left atrial pressure could increase during exercise due to impaired filling of the left ventricle by left-shift of intraventricular septum. Fourth, CPET with right heart catheterisation could not be performed at baseline because of disease severity (PVR >18 Wood units). A comparison with the haemodynamic data during exercise before therapy might have strengthened the conclusion on the effect of combination therapy on haemodynamics during exercise. Fifth, we could not evaluate arterial carbon dioxide tension and hydrogen ions because we did not collect blood samples during exercise.

\section{Conclusions}

Even after pulmonary haemodynamics at rest were remarkably improved with PAH-specific combination therapy, the pulmonary haemodynamic response to exercise remained impaired in most of the PAH patients, related to decreased ventilatory efficiency and the severity of hypoxaemia. The impairment of pulmonary haemodynamic response depended on higher MPAP and TPR at rest.

Acknowledgements: We are grateful to physical therapists Tatsuya Yasukawa, Kaori Ando, Noriko Takehara, Tetsushi Nakaji and Ayano Nakano (National Hospital Organization Okayama Medical Center, Okayama, Japan) for their assistance in performing cardiopulmonary exercise testing with right heart catheterisation.

Conflict of interest: M. Nishizaki reports personal fees from Actelion Pharmaceuticals Japan Ltd, Mochida Pharmaceutical Co. Ltd, Nippon Shinyaku Co. Ltd, Pfizer Japan Inc. and Sawai Pharmaceutical Co. Ltd, outside the submitted work. A. Ogawa reports personal fees from Actelion Pharmaceuticals Japan Ltd, Pfizer Japan Inc. and Nippon Shinyaku Co. Ltd, outside the submitted work. H. Matsubara reports personal fees from Actelion Pharmaceuticals Japan Ltd, AOP Orphan Pharmaceuticals AG, Bayer Yakuhin Ltd, GlaxoSmithKline KK, Pfizer Japan Inc., United Therapeutics Corporation, Nippon Shinyaku Co. Ltd and Kaneka Medix Corporation, outside the submitted work.

\section{References}

1 Galiè N, Humbert M, Vachiery JL, et al. 2015 ESC/ERS Guidelines for the diagnosis and treatment of pulmonary hypertension: The Joint Task Force for the Diagnosis and Treatment of Pulmonary Hypertension of the European Society of Cardiology (ESC) and the European Respiratory Society (ERS): Endorsed by: Association for European Paediatric and Congenital Cardiology (AEPC), International Society for Heart and Lung Transplantation (ISHLT). Eur Heart J 2016; 37: 67-119.

2 Barst RJ, Rubin LJ, Long WA, et al. A comparison of continuous intravenous epoprostenol (prostacyclin) with conventional therapy for primary pulmonary hypertension. N Engl J Med 1996; 334: 296-301.

3 Monaco TJ, Davila CD. Safety, efficiency, and clinical utility of macitentan in the treatment of pulmonary arterial hypertension. Drug Des Devel Ther 2016; 10: 1675-1682.

4 Sastry BKS, Narasimhan C, Reddy NK, et al. Clinical efficacy of sildenafil in primary pulmonary hypertension: a randomized, placebo-controlled, double-blind, crossover study. J Am Coll Cardiol 2004; 43: 1149-1153.

5 Galiè N, Palazzini M, Manes A. Pulmonary arterial hypertension: from the kingdom of the near-dead to multiple clinical trial meta-analyses. Eur Heart J 2010; 31: 2080-2086.

6 Ogawa A, Satoh T, Tamura Y, et al. Survival of Japanese patients with idiopathic/heritable pulmonary arterial hypertension. Am J Cardiol 2017; 119: 1479-1484.

7 McLaughlin VV, Benza RL, Rubin LJ, et al. Addition of inhaled treprostinil to oral therapy for pulmonary arterial hypertension: a randomized controlled clinical trial. J Am Coll Cardiol 2010; 55: 1915-1922.

8 Sun X-G, Hansen JE, Oudiz RJ, et al. Exercise pathophysiology in patients with primary pulmonary hypertension. Circulation 2001; 104: 429-435.

9 Simonneau G, Gatzoulis MA, Adatia I, et al. Updated clinical classification of pulmonary hypertension. J Am Coll Cardiol 2013; 62: Suppl. D, D34-D41.

10 ATS Committee on Proficiency Standards for Clinical Pulmonary Function Laboratories. ATS Statement: guidelines for the six-minute walk test. Am J Respir Crit Care Med 2002; 166: 111-117.

11 American Thoracic Society, American College of Chest Physicians. ATS/ACCP statement on cardiopulmonary exercise testing. Am J Respir Crit Care Med 2003; 167: 211-277.

12 Binder RK, Wonisch M, Corra U, et al. Methodological approach to the first and second lactate threshold in incremental cardiopulmonary exercise testing. Eur J Cardiovasc Prev Rehabil 2008; 15: 726-734.

13 Sun X-G, Hansen JE, Garatachea N, et al. Ventilatory efficiency during exercise in healthy subjects. Am J Respir Crit Care Med 2002; 166: 1443-1448.

14 West JB, Luks AM. Blood flow and metabolism: how the pulmonary circulation removes gas from the lung and alters some metabolites. In: West's Respiratory Physiology. The Essentials. 10th edn. Philadelphia, Wolters Kluwer, 2016; pp. 41-62.

15 Kovacs G, Berghold A, Scheidl S, et al. Pulmonary arterial pressure during rest and exercise in healthy subjects: a systematic review. Eur Respir J 2009; 34: 888-894.

16 Tolle JJ, Waxman AB, Van Horn TL, et al. Exercise-induced pulmonary arterial hypertension. Circulation 2008; 118: 2183-2189.

17 Lewis GD, Bossone E, Naeije R, et al. Pulmonary vascular hemodynamic response to exercise in cardiopulmonary diseases. Circulation 2013; 128: 1470-1479.

18 Blumberg FC, Riegger GJ, Pfeifer M. Hemodynamic effects of aerosolized iloprost in pulmonary hypertension at rest and during exercise. Chest 2002; 121: 1566-1571.

19 Provencher S, Hervé P, Sitbon O, et al. Changes in exercise haemodynamics during treatment in pulmonary arterial hypertension. Eur Respir J 2008; 32: 393-398.

20 Castelain V, Chemla D, Humbert M, et al. Pulmonary artery pressure-flow relations after prostacyclin in primary pulmonary hypertension. Am J Respir Crit Care Med 2002; 165: 338-340. 
21 Herve P, Lau EM, Sitbon O, et al. Criteria for diagnosis of exercise pulmonary hypertension. Eur Respir J 2015; 46: $728-737$.

22 Lewis GD, Shah RV, Pappagianopolas PP, et al. Determinants of ventilatory efficiency in heart failure: the role of right ventricular performance and pulmonary vascular tone. Circ Heart Fail 2008; 1: 227-233.

23 Johnson RL. Gas exchange efficiency in congestive heart failure. Circulation 2000; 101: 2774-2776.

24 Janicki JS, Weber KT, Likoff MJ, et al. The pressure-flow response of the pulmonary circulation in patients with heart failure and pulmonary vascular disease. Circulation 1985; 72: 1270-1278. 